\title{
Non-viral Delivery of Nucleic Acids: Insight Into Mechanisms of Overcoming Intracellular Barriers
}

\author{
Mikhail Durymanov* and Joshua Reineke* \\ Department of Pharmaceutical Sciences, College of Pharmacy and Allied Health Professions, South Dakota State University, \\ Brookings, SD, United States
}

OPEN ACCESS

Edited by:

Alexander S. Sobolev,

Lomonosov Moscow State University,

Russia

Reviewed by:

Rahul K. Keswani,

Exelead, Inc., United States

Heebeom Koo,

Catholic University of Korea,

South Korea

*Correspondence:

Mikhail Durymanov

Mikhail.Durymanov@sdstate.edu

Joshua Reineke

Joshua.Reineke@sdstate.edu

Specialty section:

This article was submitted to

Experimental Pharmacology

and Drug Discovery,

a section of the journal

Frontiers in Pharmacology

Received: 18 May 2018

Accepted: 06 August 2018

Published: 21 August 2018

Citation:

Durymanov M and Reineke J (2018)

Non-viral Delivery of Nucleic Acids:

Insight Into Mechanisms

of Overcoming Intracellular Barriers.

Front. Pharmacol. 9:971.

doi: 10.3389/fphar.2018.00971
Delivery of genes, including plasmid DNAs, short interfering RNAs (siRNAs), and messenger RNAs (mRNAs), using artificial non-viral nanotherapeutics is a promising approach in cancer gene therapy. However, multiple physiological barriers upon systemic administration remain a key challenge in clinical translation of anti-cancer gene therapeutics. Besides extracellular barriers including sequestration of gene delivery nanoparticles from the bloodstream by resident organ-specific macrophages, and their poor extravasation and tissue penetration in tumors, overcoming intracellular barriers is also necessary for successful delivery of nucleic acids. Whereas for RNA delivery the endosomal barrier holds a key importance, transfer of DNA cargo additionally requires translocation into the nucleus. Better understanding of crossing membrane barriers by nucleic acid nanoformulations is essential to the improvement of current non-viral carriers. This review aims to summarize relevant literature on intracellular trafficking of non-viral nanoparticles and determine key factors toward surmounting intracellular barriers. Moreover, recent data allowed us to propose new interpretations of current hypotheses of endosomal escape mechanisms of nucleic acid nanoformulations.

Keywords: polyplexes, lipoplexes, gene delivery, siRNA delivery, intracellular trafficking, endosomal escape

\section{INTRODUCTION}

Cancer gene therapy remains a significant challenge due to numerous barriers limiting delivery of genetic cargo. In contrast to a vast majority of nanoformulated chemotherapeutic drugs, nanoparticles for nucleic acid delivery have to reach the specific intracellular compartment; either cytosol for siRNA and mRNA, or nucleus in case of DNA. The importance of overcoming these generally conserved (applicable to numerous cell types within the cancer milieu) intracellular barriers is increasing as additional genetic manipulation technologies, such as the CRISPR/Cas9 system, will all require delivery to specific intracellular compartments to be effective and clinically relevant.

Despite advantages of viral vectors in terms of gene delivery efficacy, their use may cause immune responses and severe side effects (Raper et al., 2003; Manno et al., 2006; Howe et al., 2008) resulting in limited and very cautious clinical use. In this context, synthetic carriers able to form complexes with nucleic acids, and protect them from extra- and intracellular nucleases, are considered an alternative to viral vectors. Viral particles possess 
innate machinery to overcome cellular barriers, however, engineering of non-viral carriers requires great effort to rationally design nucleic acid nanoformulations to overcome the same barriers. Development of cationic polymers and lipids with their ability to deliver genetic material into cells gave rise to extensive studies of the mechanisms underlying transfection properties of these carriers. Obviously, this knowledge would provide the basis for future improvement of their efficacy to the level comparable with viral counterparts. To date, the progress in this direction is still insufficient.

There are numerous reviews on the topic focusing mostly on recent advances in chemistry of nanocarriers for improving nucleic acid delivery without detailed description of the mechanisms (Yao et al., 2013; Ma, 2014; Hill et al., 2016; Stewart et al., 2016a,b; Lai and Wong, 2018). The purpose of this review is to discuss intracellular barriers for non-viral delivery of nucleic acids, their significance, and mechanisms, which are exploited by different types of artificial gene carriers to overcome the key barriers. We also summarized here recent advances on how intracellular delivery of nucleic acid nanoformulations can be improved. Special attention is given to the endosomal barrier, particularly in light of recent findings obtained by time-lapse microscopy of living cells. Parallel consideration of these data and the endosome maturation process allowed us to propose our interpretation of endosomal escape mechanisms for nucleic acid nanoformulations.

\section{INTRACELLULAR TRAFFICKING OF NUCLEIC ACID NANOFORMULATIONS IN CANCER CELLS}

Similar to some types of viral vectors, artificial nanoparticles for nucleic acid delivery penetrate the cells exploiting endocytic mechanisms. Nanoparticles can enter cancer cells via different types of endocytosis and/or macropinocytosis (Figure 1). Internalization through phagocytic pathways occurs primarily in monocytes/macrophages, neutrophils, and dendritic cells (Sahay et al., 2010), and usually is not attributed to cancer cells.

Upon uptake, endosomal vesicles undergo a maturation process driven mainly by phosphatidylinositols (PIs) in the cytosolic leaflet of the vesicle bilayer (Bohdanowicz and Grinstein, 2013) and Rab GTPases (Hutagalung and Novick, 2011). During maturation, biochemical characteristics and morphology of vesicles significantly change (Figure 1). In particular, early endosomes lose tubular membrane structures which become the endocytic recycling compartment and provide retrograde transport of phospholipids and receptors to plasma membrane. Some fraction of internalized nanoparticles with genetic payload might be recycled by this route (Gonçalves et al., 2004; Sahay et al., 2013), but this process seems to depend on physicochemical properties of nanoparticles and cancer cell type. The membranes of early endosomal compartments are enriched with phosphatidylinositol 3-phosphate (PI3P), which provides interaction of the vesicle with cytosolic early endosome antigen 1 (EEA1), an endosomal sorting complex required for transport (ESCRT) machinery, and Rab5 GTPase (Bohdanowicz and Grinstein, 2013). All these proteins are required for sorting and progression of early endosomal vesicles to degradative compartments. It should be noted, that internalized nucleic acid nanoformulations are sorted to this degradative pathway. Maturation of early endosomes leads to their transformation into multivesicular bodies (MVBs) containing intraluminal vesicles (ILVs). This process is mainly governed by gradual replacement of Rab5 with Rab7, which regulates endo-lysosomal morphogenesis (Hutagalung and Novick, 2011). MVBs are characterized by an acidic luminal pH promoted by $\mathrm{V}$-type $\mathrm{H}^{+}$-ATPase. Moreover, MVBs gradually acquire bis(monoacylglycero)phosphate (BMP), also known as lysobisphosphatidic acid (LBPA), which along with ESCRT-III complex is involved into ILV formation (Williams and Urbé, 2007; Bissig and Gruenberg, 2014). Further conversion of MVBs to late endosomes leads to elevation of Rab7 and BMP/LBPA content, and increase of ILV number due to inward budding of the MVB limiting membrane. Additionally, the limiting membranes of late endosomal compartment contain a high level of phosphatidylinositol $(3,5)$-bisphosphate $\left[\mathrm{PI}(3,5) \mathrm{P}_{2}\right]$, which regulates sorting of endocytic membranes for delivery to the trans-Golgi network (Bohdanowicz and Grinstein, 2013). This mechanism of trans-Golgi network-mediated transport also may contribute to partial recycling of nucleic acid nanoformulations to the extracellular milieu (Sahay et al., 2013). Transformation of late endosomes into lysosomes is accompanied by acquisition of lysosomal-associated membrane proteins (LAMPs), formation of multilaminar structures enriched with BMP/LBPA (Möbius et al., 2003), highly acidic $\mathrm{pH}$ level, and activation of lysosomal hydrolases which can destroy genetic payloads of therapeutic nanoparticles. For successful delivery of nucleic acids, overcoming endosomal barrier is mandatory and preferable before conversion of endosomes into lysosomes with activated hydrolases (Figure 1).

For delivery of DNA another essential barrier is the passage through the nuclear envelope. Nuclear entry of macromolecules occurs via channels of the nuclear pore complex (NPC) in a size-dependent manner. For example, macromolecules with size less than $9 \mathrm{~nm}$ (or $40 \mathrm{kDa}$ molecular weight) are able to diffuse passively through the NPC. Import of larger molecules can occur through an energy- and signal- dependent active process (Talcott and Moore, 1999; Gamini et al., 2014). Regarding DNA transfer, microinjection experiments have shown that 200-300 bp is the maximal length of linear DNA that can cross the NPC relatively freely (Ludtke et al., 1999). Since the average length of therapeutic gene expression cassettes are a few kbp, their NPC-mediated transfer into the nucleus is improbable. However, a nuclear envelope temporarily breaks down during mitosis and provides opportunity for DNA translocation to the nuclei of daughter cells, although non-identified mitosis-independent mechanism also can be involved into DNA uptake by the nucleus (Figure 1).

Thus, delivery of genetic cargo to cytosol or nucleus is a complicated multi-step process affected by numerous factors. The success of nucleic acid delivery is a result of overcoming all mentioned barriers for which mechanisms and impacts are discussed below. 


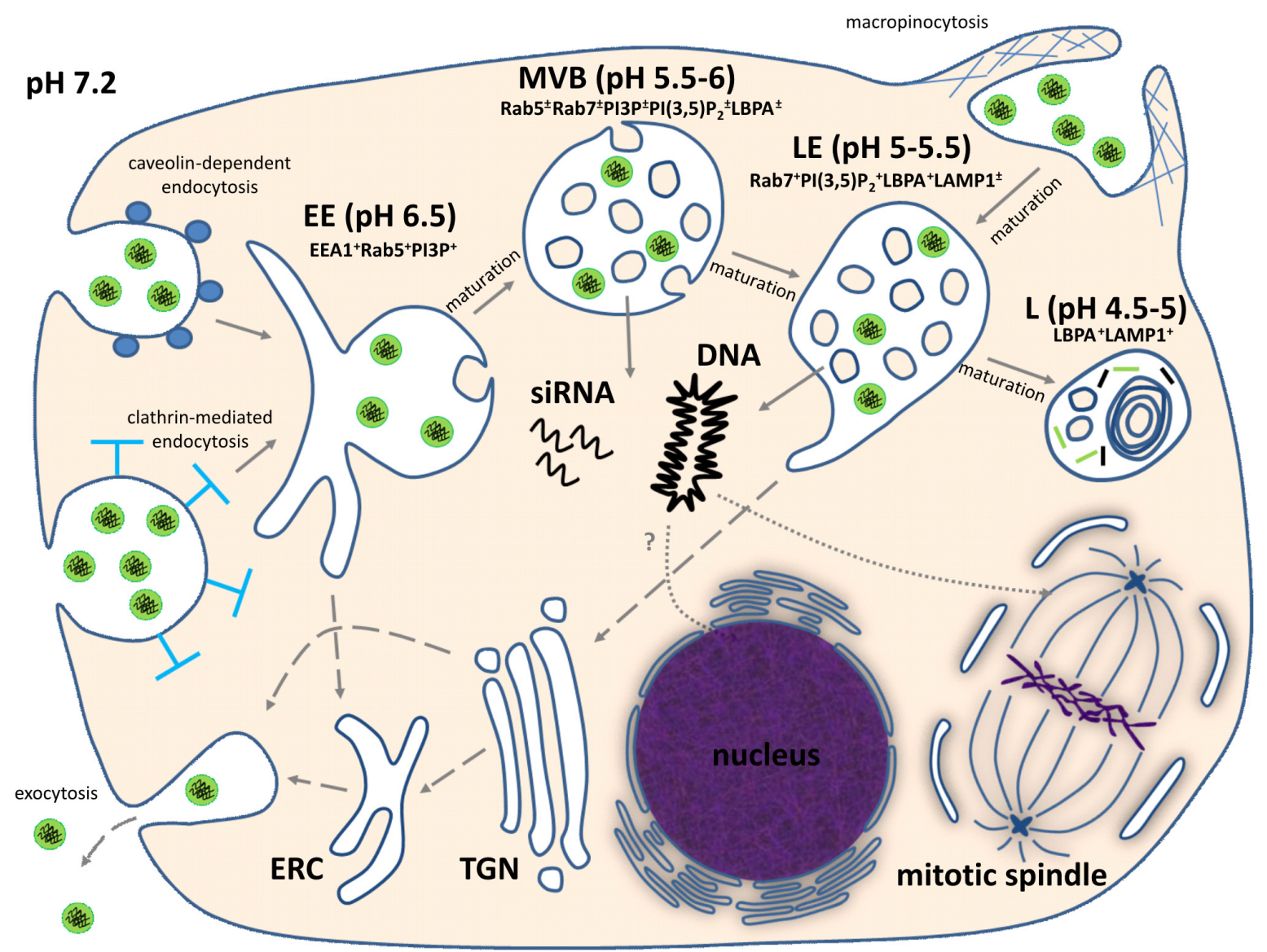

FIGURE 1 | Intracellular trafficking of non-viral nucleic acid nanoformulations. Comments can be found in the text. EE, early endosome; MVB, multivesicular body; LE, late endosome; L, lysosome; ERC, endocytic recycling compartment; TGN, trans-Golgi network; EEA1, early endosome antigen 1; PI3P, phosphatidylinositol 3-phosphate; $\mathrm{PI}(3,5) \mathrm{P}_{2}$, phosphatidylinositol $(3,5)$-bisphosphate; LBPA, lysobisphosphatidic acid; LAMP1, lysosomal-associated membrane protein 1. "+" and " \pm " mean high and moderate levels of abundance, respectively.

\section{INTERNALIZATION OF NANOPARTICLES WITH GENETIC PAYLOAD}

Endocytic routes are the primary internalization mechanism for nucleic acid nanoformulations. Although non-endocytic mechanisms such as fusion of lipoplexes with the plasma membrane and pore formation on the cell membrane have been reported, the data confirming their involvement in nucleic acid delivery process are controversial, and direct proofs are still lacking (Xiang et al., 2012). Since endocytic pathways of nonviral carriers have been thoroughly analyzed in numerous reviews (Xiang et al., 2012; El-Sayed and Harashima, 2013; Perez Ruiz de Garibay, 2016), here, we will focus only on a few aspects of endocytosis which affect transfection efficacy.

To date, only four endocytic pathways of non-viral nanoparticle uptake have been determined for cancer cells including clathrin-dependent, caveolae-dependent, flotillinmediated, and macropinocytosis (Perez Ruiz de Garibay, 2016). The determination of endocytic route depends on multiple factors including both cell line and nanocarrier parameters such as chemical nature, presence of ligand moiety, and nanoparticle size and surface charge (Xiang et al., 2012). It is generally accepted that positive charge promotes nanoparticle interaction with anionic glycosaminoglycans on the cell surface and enhances their uptake (Kopatz et al., 2004). Of importance to emphasize is that all endocytic pathways result in the endolysosomal system pathway. It has been hypothesized earlier that targeting caveolae-mediated pathway can avoid a lysosomal destination for nucleic acid nanoformulations (Rejman et al., 2005). However, later study of this type of endocytosis confirmed lysosomal transport of the internalized cargo (Engel et al., 2011). Despite similarity in the trafficking pathway, the specific endocytic pathway affects kinetics of non-viral nanocarrier internalization and total uptake potential. Some studies for both lipoplex (Sakaguchi et al., 2008) and polyplex (Trusov et al., 2011; Ulasov et al., 2011) nanoparticles demonstrated positive correlation of internalization rate and transfection efficacy. Additionally, importance of increasing uptake as a design criteria for nanocarriers was indicated by Bishop et al. The authors found that an insignificant amount of poly(beta-amino ester)-based polyplexes was internalized by human glioblastoma cells in 2D culture (Bishop et al., 2016). In this connection, 
modification of RNA- or DNA- containing nanoparticles with a ligand moiety seems to be beneficial because it facilitates binding of these nanoformulations with the cell surface and induces their endocytosis in a complex with rapidly internalizing receptors. As a result, improved transfection efficacies of cancer cells have been observed for nanovehicles containing a ligand to transferrin (Sakaguchi et al., 2008; Zhang et al., 2015), $\alpha_{\nu} \beta_{3}$ integrin (Ng et al., 2009; Mohammed-Saeid et al., 2017), melanocortin-1 (Durymanov et al., 2012), EGF (Kloeckner et al., 2006), and folate (Liu et al., 2012; Jones et al., 2016) receptors as compared with non-targeted counterparts. Additionally, it cannot be excluded that nanoparticle internalization in a complex with some of the mentioned receptors might decrease the rate of the recycling process via the exocytosis pathway, which was reported for non-targeted lipid nanoparticles (Sahay et al., 2013) and polyplexes (Gonçalves et al., 2004).

\section{ENDOSOMAL ESCAPE}

\section{Lipoplex-Formulated Release of Genetic Payload From Endosomes}

In recent years, a substantial breakthrough in elucidation of endosomal escape of nucleic acid nanoformulations has been achieved due to the use of spinning-disk microscopy for observation of nanoparticle intracellular trafficking in real time. Exploiting this technique has shown that Lipofectamine 2000based lipoplexes release their genetic payload (siRNA) starting after 5-15 min of uptake by HeLa cells. Endosomal release of siRNA occurs instantly, and is followed by rapid (10-20 s) diffusion of siRNA throughout entire cytosol (Figure 2A). At the same time, a significant fraction of cargo stayed within endosomes as well as the lipid part of lipoplex (ur Rehman et al., 2013; Wittrup et al., 2015). Thus, genetic payload is released uncoated. It was also found that endosomal escape takes place in vesicles with $\mathrm{EEA} 1^{-} \mathrm{Rab}^{+} \mathrm{Rab}^{+}{ }^{+} \mathrm{Rab}{ }^{ \pm}{ }^{\mathrm{LAMP}} 1^{-}$ phenotype that corresponds to maturing but not late endosomes. Further, inhibition of endosome acidification with bafilomycin A impaired efficacy of gene silencing by $10-40 \%$ depending on siRNA dose (Figure 2B) (Wittrup et al., 2015).

These findings generally do not contradict an earlier proposed explanation of lipoplex endosomal escape, also known as "lipid-mixing" mechanism. This hypothesis was suggested in 1996 basing on in vitro mimicking of lipid/DNA nanoparticle interactions with membranes containing the negatively charged phospholipid phosphatidylserine (PS) (Xu and Szoka, 1996). According to this hypothesis, lipid/DNA (or lipid/RNA) complexes destabilize endosomal membrane due to flip-flop translocation of anionic lipids (mainly PS) from cytosolic leaflet to luminal side. Following this, these negatively charged phospholipids electrostatically interact with cationic lipids in lipoplexes resulting in displacement of genetic cargo. This then leads to production of non-bilayer structures (inverted hexagonal $\mathrm{H}_{\|}$phase) in endosomes and release of nucleic acids to the cytosol (Xu and Szoka, 1996; Hafez et al., 2001).

However, some questions still remain. For example, why lipoplexes discharge genetic payload in maturing endosomes, whereas the PS content in these compartments is as a minimum twofold less than in early endosomes (Kobayashi et al., 1998)? Why a pH-dependence of endosomal escape has been observed? Probably, more detailed consideration of endosome maturation process may help to find possible explanations of these facts. It should be noted that besides PS, there are other negatively charged lipids in the endosomal bilayer such as phosphatidylinositols $\mathrm{PI} 3 \mathrm{P}$ and $\mathrm{PI}(3,5) \mathrm{P}_{2}$. However, they are also localized in the cytosolic leaflet of endosomal bilayers with PS, and their abundance is relatively low. An additional consideration is that MVBs are enriched with BMP/LBPA, an unconventional anionic phospholipid, which may play a primary role in endosomal release of genetic payload from lipoplexes.

To determine localization of BMP/LBPA in MVBs, some studies with monoclonal antibody $6 \mathrm{C} 4$ against this phospholipid were carried out. Microinjection of this antibody into cells did not lead to MVB/lysosome targeting, but it was obtained after staining with prior fixation and permeabilization. Additionally, fluorescence correlation spectroscopy demonstrated that $6 \mathrm{C} 4$ only binds sonicated, but not intact late endosomes (Kobayashi et al., 2001). Therefore, obtained results revealed the lack of BMP/LBPA in cytosolic leaflet. Furthermore, anti-BMP/LBPA antibodies demonstrated high co-localization extent with membranes of ILVs, and only minor presence in limiting MVB membrane at sites of intraluminal invaginations (Kobayashi et al., 1998, 2001; Möbius et al., 2003). It means that cationic lipids of lipoplex can directly interact with BMP/LBPA-rich areas on the luminal side of limiting MVB and ILV membranes. It is thought that in mammalian cells BMP/LBPA may be involved in ILV formation along with ESCRT due to inward budding of the limiting MVB membrane (Falguières et al., 2009). BMP/LBPA is an inverted cone-shaped phospholipid (Williams and Urbé, 2007) promoting positive membrane curvature (Harayama and Riezman, 2018). It has been shown in vitro that BMP/LBPA-containing liposomes are able to form ILVs at acidic intraluminal $\mathrm{pH}$ ( $\mathrm{pH}$-dependent) resembling MVBs (Matsuo et al., 2004). Perhaps, acidification of endosomal lumen causes partial protonation of phosphate groups of BMP/LBPA that minimizes electrostatic repulsion of anionic headgroups and alleviates clustering of BMP/LBPA favoring inward curvature of the limiting membrane toward endosome lumen. Inhibition of endosomal acidification might impede BMP/LBPA clustering and interaction with positively charged lipoplexes decreasing efficacy of endosomal escape.

Thus, BMP/LBPA is a stronger candidate for induction of nucleic acid endosomal escape than PS because it can directly interact with positively charged lipoplexes at areas of MVB limiting membrane invaginations (Figure 2C), whereas PS flipping from cytosolic leaflet is thermodynamically restricted because of charged headgroups (Sprong et al., 2001). Furthermore, PS has a cylindrical shape, favoring bilayer formation (Sprong et al., 2001), whereas BMP/LBPA is a wedge-shaped phospholipid which destabilizes the bilayer phase upon interaction with cationic cone-shaped lipids. As was mentioned above, the phenotype of endosomes where release of genetic cargo occurs coincides with MVBs and start of BMP/LBPA generation. Finally, our hypothesis about the 
A

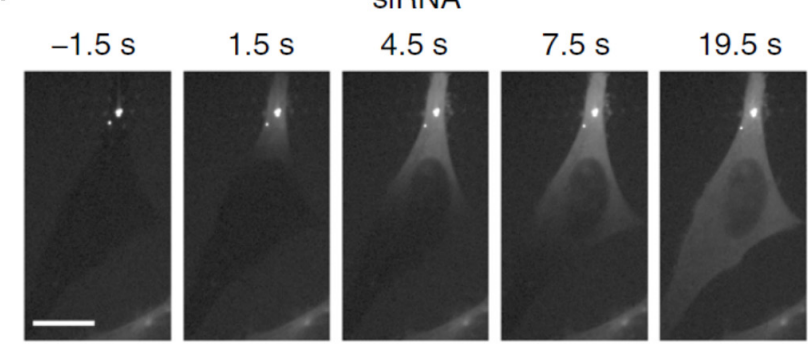

B

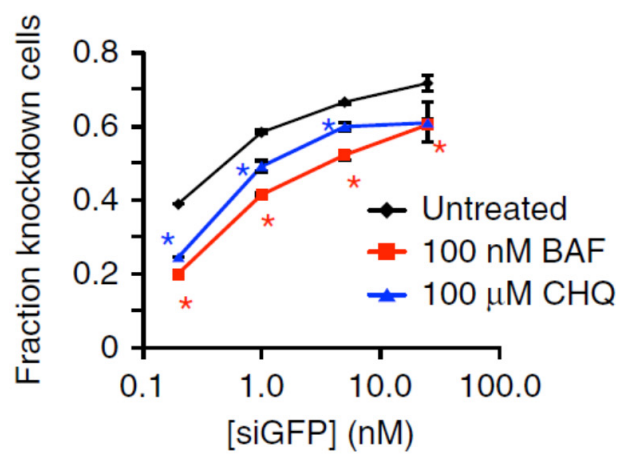

C

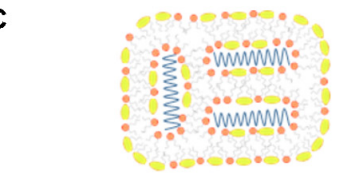

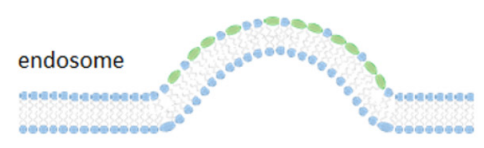

cytosol

言 nucleic acid

BMP/LBPA

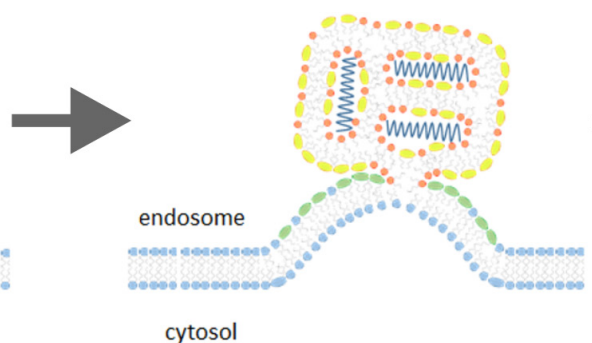

cytosol

neutral membrane phospholipid

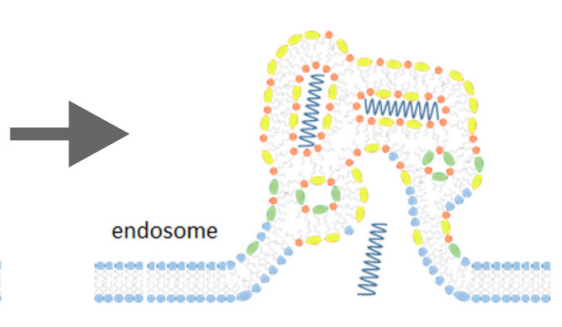

cytosol

FIGURE 2 | Lipoplex endosomal escape. Escape of lipoplex-formulated genetic cargo from an endosome in HeLa cells takes seconds followed by diffusion of siRNA throughout entire cytosol (A). Efficacy of GFP knockdown in HeLa-GFP cells upon incubation with lipoplexes carrying siGFP in the presence of inhibitors of endosomal acidification bafilomycin A1 (BAF) or chloroquine (CHQ) (B). "Lipid-mixing" mechanism of endosomal escape of lipoplex-formulated nucleic acids in assumption of primary role of BMP/LBPA, concentrated in the luminal leaflet of endosomal membrane in area of ILV formation (see the text for additional comments) (C). (A,B) Figures are reprinted by permission from Nature Publishing Group (Wittrup et al., 2015).

primary role of $\mathrm{BMP} / \mathrm{LBPA}$ in endosomal release may explain why inhibition of $\mathrm{pH}$ affects siRNA-mediated knockdown efficacy.

\section{Overcoming Endosomal Barrier by Polyplexes}

Intravital microscopy enabled valuable information to be obtained about intracellular trafficking and endosomal release of polyplex-formulated siRNA and plasmid DNA. It was found that polyethylenimine (PEI)-based polyplexes escape from endosomes at approximately $30 \mathrm{~min}$ after uptake by HeLa cells. This process occurs instantly and is accompanied by partial release of PEI together with genetic payload. Discharge of genetic payload in case of polyplexes occurs from LAMP-1-positive vesicles corresponding to late endosomes/lysosomes (ur Rehman et al., 2013). Furthermore, endosomal acidification plays a crucial role in endosomal escape because both genetic cargo release and transfection efficacy were virtually inhibited by bafilomycin A (Kichler et al., 2001; ur Rehman et al., 2013).

Interestingly, endosome acidification plays a key role in the "proton sponge" hypothesis mechanism of polyplex endosomal escape proposed over 20 years ago (Boussif et al., 1995). This hypothesis postulates that the buffering capacity of polyamine carriers leads to osmotic rupture of endosomal membrane and release of polyplexes into cytosol. Experiments with PEI-treated cells demonstrated increased accumulation of endosomal chloride (Figure 3A) responsible for osmotic swelling of endosomes, followed by the lysis of endocytic PEI-containing vesicles that supported the "proton sponge" hypothesis (Sonawane et al., 2003). However, a more recent study detected no change in endosomal $\mathrm{pH}$ within vesicles containing PEI (Figure 3B), whereas according to the "proton sponge" mechanism, $\mathrm{pH}$ should increase due to PEI buffering capacity (Benjaminsen et al., 2013). This contradiction strongly challenged the "proton sponge" hypothesis. At the same time, different polyamines including poly-L-lysine, poly(amidoamine) and PEI can permeabilize supported lipid bilayers and even cell plasma membranes (Hong et al., 2006) that may also explain endosomal escape. Experimental data with bafilomycin A confirmed the importance of endosome acidification as mentioned above. It was also found that endosomal escape does not lead to complete endosome rupture as the "proton sponge" hypothesis postulates. Additionally, release of polyplex-formulated fluorescently labeled siRNA from endosomes spreads in a single direction (Figure 3C) (ur Rehman et al., 2013).

Our interpretation of these experimental data considers direct interaction of cationic part of polyplexes with negatively charged 


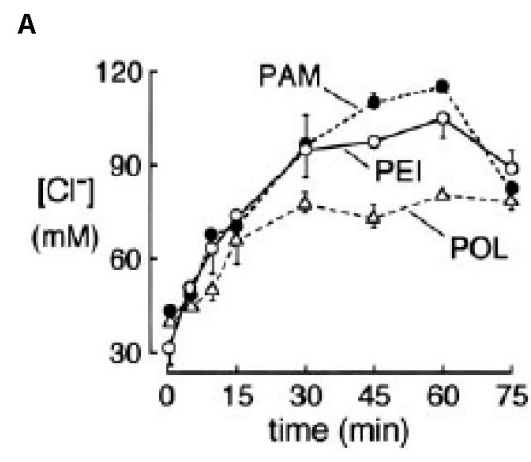

C
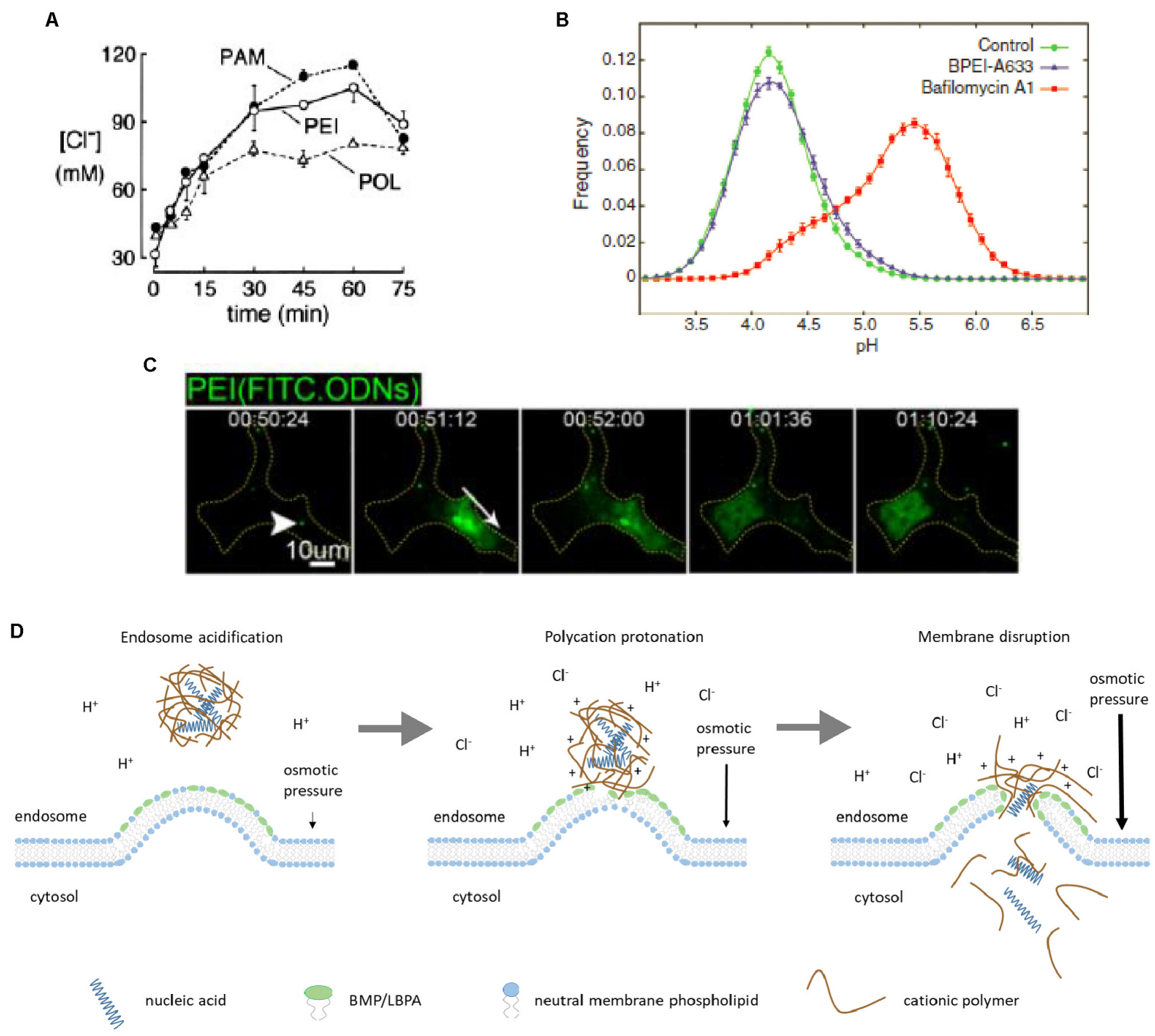

FIGURE 3 | Polyplex endosomal escape. Accumulation of chloride in endosomal vesicles upon cellular uptake of polyamidoamine (PAM), polyethylenimine (PEI), and polylysine (POL) reflects higher buffering capacity of PAM and PEI (A). Lack of acidic endosomal pH increase in vesicles containing branched PEI (BPEI), compared to bafilomycin A-treated cells, contradicts the "proton sponge" hypothesis (B). Released polyplex-formulated genetic cargo (FITC-labeled oligodeoxyribonucleotides, ODNs) from an endosome in HeLa cells spreads in a single direction (white arrow) (C). Proposed mechanism of endosomal escape of polyplex-formulated nucleic acids driven by osmotic pressure and local permeabilization of endosomal membrane due to electrostatic interactions between polycation and anionic phospholipids like BMP/LBPA (D). Figure adapted with permission from: (A) (Sonawane et al., 2003), ASBMB; (B) (Benjaminsen et al., 2013), Elsevier; (C) (ur Rehman et al., 2013), copyright (2013) American Chemical Society.

phospholipids, primarily with BMP/LBPA. Regarding buffering properties of the carriers, they could significantly facilitate endosomal escape. First, protonation of polycation may lead to more strong electrostatic interaction with negatively charged lipids, resulting in membrane permeabilization. Second, even though luminal $\mathrm{pH}$ does not increase, influx of chloride ions promotes osmotic swelling of endosomes. Upon reaching a critical value, osmotic pressure imparts mechanical impulse to nucleic acids and part of associated polycation leading to their discharge from endosome (Figure 3D). According to our model, both buffering capacity of polycation and its ability to interact with anionic lipids like BMP/LBPA and permeabilize endosomal membrane are important for endosomal escape.

\section{Crossing Endosomal Barrier by Inorganic Nanoparticles}

Besides lipid- and polycation-based delivery systems, there are several types of inorganic materials which are exploited for nucleic acid delivery to tumors. Among them, calcium phosphate $(\mathrm{CaP})$ composite is the oldest non-viral gene carrier; introduced in 1973 (Graham and van der Eb, 1973). CaP is a biocompatible and degradable material able to form a complex 
with nucleic acids and successfully deliver them to cells (Yao et al., 2013). Despite many years of use of this transfection agent, the mechanisms of overcoming the endosomal barrier remain elusive. In a study by $\mathrm{Li}$ et al. (2010), it was proposed that endosomal release of nucleic acids delivered by $\mathrm{CaP}$ is an osmotically driven process. Low luminal $\mathrm{pH}$ causes rapid dissolving of $\mathrm{CaP}$ that results in an increase of osmotic pressure and rupture of endosomal vesicles. One of the most important limitations of $\mathrm{CaP}$ precipitates is control of their size because CaP crystals grow over time (Ramamoorth and Narvekar, 2015). However, PEG conjugation or lipid coating approaches improved colloidal stability of these nanocarriers and led to clinically relevant in vivo efficacies (Ma, 2014; Pittella et al., 2014). Probably, increased interest to these delivery vehicles will result in more efforts to study endosomal nucleic acid release mechanisms.

Gold nanoparticles are promising inorganic materials for gene-based therapy of cancer. Their physical properties make it possible to cause plasmon resonance after near infrared (NIR) irradiation and control nucleic acid release via thermal and non-thermal mechanisms (Huschka et al., 2011, 2012). Along with controlled release of genetic payloads, NIR irradiation also causes endosomal disruption. At least two possible mechanisms are reported to be involved in endosomal escape depending on the mode of NIR irradiation. For both pulsed and continuous wave irradiation of high laser intensity, a thermal mechanism plays the major role (Carregal-Romero et al., 2012). Local heating of the surrounding area induces enhanced mobility and oscillations of endosomal phospholipids resulting in high membrane leakiness (Stewart et al., 2016b). However, endosomal escape of gold nanoparticles can be induced by low intensities of NIR irradiation. Authors also detected enhanced photochemical generation of reactive oxygen species (Krpetic et al., 2010), which can be an underlying mechanism of endosomal vesicles disruption resulting in release of nanoparticles into the cytosol. Thus, light-induced endosomal escape of gold nanoparticles potentially may improve selectivity of nucleic acid delivery to localized tumors.

Carbon nanotubes have a unique property of endocytosisindependent cell penetration due to the so-called "needle" mechanism and may completely avoid the endosomal barrier (Pantarotto et al., 2004). Thus, they are a promising carrier for nucleic acids transfer, though this gives rise to a potential issue of off-target delivery. However, several recent studies have challenged endocytosis-independent cellular internalization of carbon nanotubes (Kam et al., 2006; Becker et al., 2007), though the uptake pathway seems to depend on the length of nanotubes (Caoduro et al., 2017). Regardless, additional strategies have been proposed to improve nucleic acid delivery with carbon nanotubes (Li et al., 2015).

Two other types of inorganic delivery vehicles, namely, silicabased (Niut et al., 2012) and superparamagnetic iron oxide (Taratula et al., 2011; Luo et al., 2017) nanoparticles have been proposed as nucleic acid carriers due to their enhanced loading capacity and the possibility to monitor biodistribution, respectively. These materials cannot innately promote endosomal disruption and need additional chemical modifications to tune their endosomal escape capabilities.

\section{Strategies to Improve Endosomal Escape}

It should be noted that there are numerous additional endosomal escape approaches for nucleic acid nanoformulations

TABLE 1 | Main strategies to facilitate endosomal escape of nucleic acid nanoformulations.

\begin{tabular}{|c|c|c|}
\hline Strategy & Mechanism & Selected references \\
\hline $\begin{array}{l}\text { Co-delivery with } \\
\text { lysosomotropic agent }\end{array}$ & $\begin{array}{l}\text { Buffering luminal } \mathrm{pH} \text {, osmotic swelling of } \\
\text { endosomal vesicles }\end{array}$ & $\begin{array}{l}\text { Mesoporous silica nanoparticles conjugated with PEG and } \\
\text { PDEAEMA for delivery of DNA or siRNA. Loading of these } \\
\text { particles with chloroquine significantly improved efficacy of } \\
\text { gene delivery or gene silencing in B16F10 melanoma cells } \\
\text { (Bhattarai et al., 2010) }\end{array}$ \\
\hline $\begin{array}{l}\text { Co-delivery with } \\
\text { photosensitizers }\end{array}$ & $\begin{array}{l}\text { Light-induced generation of reactive oxygen } \\
\text { species and lipid oxidation result in enhanced } \\
\text { permeability of endosomal membrane }\end{array}$ & $\begin{array}{l}\text { Micelles based on triblock copolymer/DNA/dendrimeric } \\
\text { photosensitizer caused 100-fold photoenhanced gene } \\
\text { expression in HeLa cells and site-specific transfection of } \\
\text { tumors (Nomoto et al., 2014) }\end{array}$ \\
\hline $\begin{array}{l}\text { Chemical functionalization with } \\
\text { CPPs: } \\
\text { - TAT peptide } \\
\text { - Pore-forming peptides } \\
\text { - Fusion peptides }\end{array}$ & $\begin{array}{l}\text { - For TAT peptide the mechanism is unclear } \\
\text { - Pore-forming and fusion peptides upon endosomal } \\
\text { acidification undergo transition from random coil } \\
\text { (pH 7) to } \alpha \text {-helical ( } \mathrm{pH} \text { 5.5) conformation that } \\
\text { increases hydrophobic interaction of peptide and } \\
\text { membrane bilayer }\end{array}$ & $\begin{array}{l}\text { - Intratumorally injected TAT-modified DNA-containing } \\
\text { liposomes much more effectively transfected Lewis lung } \\
\text { carcinoma tumors than unmodified counterparts (Torchilin } \\
\text { et al., 2003) } \\
\text { - Polyplexes conjugated with melittin caused effective gene } \\
\text { silencing in H1299 lung carcinoma cells and in lung tissue } \\
\text { upon intratracheal administration (Feldmann et al., 2018) }\end{array}$ \\
\hline Incorporation of polyamines & $\begin{array}{l}\text { Osmotic swelling and electrostatic interaction with } \\
\text { endosomal membrane }\end{array}$ & $\begin{array}{l}\text { Cyclodextrin and PEl functionalized mesoporous silica } \\
\text { nanoparticles efficiently accumulated in MDA-MB-231 } \\
\text { tumors and caused gene silencing (Shen et al., 2014) }\end{array}$ \\
\hline $\begin{array}{l}\text { Incorporation of amphiphatic } \\
\text { polycations }\end{array}$ & $\begin{array}{l}\text { Perturbation of endosomal membrane after } \\
\mathrm{pH} \text {-triggered dissociation of shielding moieties }\end{array}$ & $\begin{array}{l}\text { DPCs comprising PBAVE conjugated via pH-triggered } \\
\text { linkers with siRNA, PEG and GalNAc were able to effective } \\
\text { delivery of genetic cargo to hepatocytes in vitro and in vivo } \\
\text { and cause significant gene silencing (Rozema et al., 2007) }\end{array}$ \\
\hline
\end{tabular}


(Stewart et al., 2016a) (Table 1). First, co-treatment of cells with lysosomotropic agents such as chloroquine, sucrose, polyvinylpyrrolidone (PVP) and others can be used (Ciftci and Levy, 2001; Cheng et al., 2006). These agents accumulate in endosomes together with gene delivery nanoparticles, cause $\mathrm{pH}$ buffering and induce osmotic swelling of endosomal vesicles, minimizing damage of nucleic acid cargo and promoting more efficient release into cytosol. Chloroquine is the most widely used lysosomotropic agent. However, in spite of its relatively high in vitro efficacy and successful attempt of use to promote polyplex-mediated gene delivery to liver (Zhang et al., 2003), in vivo translation of this approach is limited because of high systemic toxicity (Cann and Verhulst, 1961). On the other hand, co-encapsulation of chloroquine with DNA or RNA in a single particle may overcome the need for systemic treatment. Bhattarai et al. (2010) fabricated mesoporous silica nanoparticles conjugated with PEG and poly(2-(dimethylamino)ethylmethacrylate) (PDEAEMA) for delivery of DNA or siRNA. Loading of these particles with chloroquine significantly improved efficacy of gene delivery or gene silencing in B16F10 melanoma cells. However, this strategy still has not been tested in vivo.

The second approach facilitating non-viral transfection is treatment of cells with photosensitizers, also known as "photochemical internalization" (Oliveira et al., 2007; Zamora et al., 2014). Upon uptake, photosensitizers cause light-induced oxidative disruption of endosomal membranes resulting in enhanced gene delivery (Selbo et al., 2010). It should be noted that photosensitizers are widely used for photodynamic therapy and considered as safe agents for systemic administration. However, for better efficacy, the photosensitizer should be incorporated into the structure of the gene delivery nanocarrier. The advantage of this approach has been demonstrated in vivo for nanoparticles comprising of plasmid DNA as the genetic payload, PEG-poly $\{\mathrm{N}$ [N-(2-aminoethyl)-2-aminoethyl]aspartamide\}-poly(L-lysine) for DNA complexation and providing long circulation, and dendrimeric phthalocyanine as the photosensitizer. Obtained micelles demonstrated 100-fold photoenhanced gene expression in HeLa cells and site-specific transfection of tumor cells (Nomoto et al., 2014).

Another method for improvement of endosomal escape of non-viral vectors is modification of their surface with cellpenetrating peptides (CPPs). Numerous peptidic moieties have been proposed for this aim including fusogenic virus-derived (Wagner et al., 1992) or synthetic peptides such as GALA (Simões et al., 1999) and KALA (Min et al., 2006), or pore-forming viral- (Zauner et al., 1995) and bacterial-derived (Saito et al., 2003; Lorenzi and Lee, 2005) peptides. Moreover, peptides from insect venoms such as melittin have been extensively studied for optimization of lipoplex- and polyplex-mediated transfection of fibroblasts (Legendre et al., 1997), H1299 lung carcinoma cells and lung tissue (Feldmann et al., 2018). All these peptides have a similar mechanism of membranotropic activity, mediated by a change of endosomal $\mathrm{pH}$. Acidification of the endosomal lumen leads to conformational transition of these peptides from a random coil to an amphipathic $\alpha$-helix, which interacts with membrane phospholipids and causes pore formation or fusion of endosomal membrane with, for example, the viral envelope (Varkouhi et al., 2011). Another example of CPP is TAT peptide derived from the transcriptional activator protein of human immunodeficiency virus type 1 (HIV-1). Although the mechanisms of membrane disruption caused by TAT peptide are unclear, it was successfully exploited in vivo to improve local polyplex-mediated gene delivery to lung tissue (Kleemann et al., 2005) and Lewis lung carcinoma tumors (Torchilin et al., 2003). In spite of improvement in transfection efficacy, clinical translation of delivery systems comprising peptide moieties holds potential immunogenicity concerns.

As mentioned previously, there are some inorganic nanocarriers for nucleic acid delivery which are unable to induce endosomal escape. Their modification with polyamines, such as poly(amidoamine)s or PEI, facilitate endosomal release and significantly enhances transfection efficacy both in vitro and in vivo (Shen et al., 2014; Ngamcherdtrakul et al., 2015; Luo et al., 2017).

Finally, incorporation of amphiphatic polycations (Wakefield et al., 2005) into carriers can also improve endosomal release of nucleic acids. As an example of this approach, dynamic polyconjugates (DPCs) developed for siRNA delivery to hepatocytes contain membrane-active poly(vinyl ether) polymer, termed PBAVE. This polymer is shielded by PEG for prolonged circulation and $N$-acetylgalactosamine (GalNAc) moieties for targeting hepatocytes (Rozema et al., 2007). Positive pre-clinical results (99\% silencing of liver genes in non-human primates) made it possible to begin clinical trials of this approach (Yin et al., 2014). Harnessing of this technology for tumor-targeted siRNA delivery holds a great promise for anti-cancer gene therapy.

\section{NUCLEAR ENTRY OF DNA}

Transcription of foreign DNA requires its nuclear-targeted delivery. However, only relatively short DNA fragments (less than 200-300 bp) are able to penetrate the nucleus by passive diffusion through the NPC (Ludtke et al., 1999). As far as the approximate length of therapeutic DNA reaches some kbp, its delivery to the nucleus via NPC is highly challenging and unlikely. Some attempts to improve NPC-mediated DNA delivery have been made (Table 2). The first approach considered covalent conjugation of DNA with a peptidic nuclear localization signal (NLS), responsible for active importin-mediated nuclear transfer of large cytoplasmic proteins. This approach improved nuclear transfer of plasmid DNA with attached SV40 viral NLS peptide in digitonin-permeabilized cells, but not in intact cells after microinjection of the modified DNA (Sebestyén et al., 1998). The similar approach in relation to linear $3.3 \mathrm{kbp}$ DNA largely enhanced its nuclear uptake (Zanta et al., 1999), but a later study indicated that there is no benefit of NLS conjugation to DNA for improved gene delivery with non-viral carriers (van der Aa et al., 2005). Another approach considered inclusion of nucleotide sequences into DNA which can be recognized by cytoplasmic transcription factors containing NLS, and then transported into the nucleus (Dean et al., 1999; Mesika et al., 2001). However, nuclear translocation of cytoplasmic 
transcription factors requires activation of certain signaling pathways in cancer cells that strongly limits application of this approach. Furthermore, this technology has not been validated in vivo. Next, the use of trans-cyclohexane1,2-diol (TCHD) was proposed to improve NPC-mediated nuclear uptake of DNA. This amphipathic alcohol temporary perturbed the barrier function of the NPCs and facilitated nuclear entry of dextrans and naked plasmid DNA. Moreover, TCHD treatment of cells enhanced lipoplex-mediated transfection (Vandenbroucke et al., 2007). However, application of this strategy is also limited by toxicology aspects of TCHD use in vivo. It should be noted that the barrier function of NPC can be decreased by conjugation of gene delivery nanocarriers with a ligand moiety to the cytoplasmic glucocorticoid receptor. Interaction with this receptor induces NPC dilation up to $300 \mathrm{~nm}$ in diameter and nuclear translocation of ligand/receptor complex (Yao et al., 2013). The advantage of this strategy was shown for polyplexes based on hyaluronic acid (HA)-PEI-dexamethasone block-copolymer. These nanoparticles displayed higher efficacy of gene delivery to cancer cells and tumors compared with nonmodified counterparts (Fan et al., 2013). Targeting a nanocarrier with all-trans-retinoic acid (ATRA) to cytoplasmic retinoic acid receptor also promotes nuclear translocation of ligand/receptor complex via a similar mechanism as in the case of glucocorticoid receptor. In spite of promising in vitro results for ATRAtargeted polyplex-based carriers (Park et al., 2009), in vivo translation of this strategy for cationic liposomes did not lead to enhanced efficacy of gene delivery as compared with non-targeted counterparts (Charoensit et al., 2010). However, they demonstrated improved anti-tumor effect presumably due to ATRA-mediated TNF- $\alpha$-induced apoptosis in cancer cells (Charoensit et al., 2010).

It is commonly accepted that the primary way of foreign DNA entry is a passive entrapment during mitosis, when the nuclear envelope is disassembled starting from late prophase up to late anaphase, and its components (proteins and membranes) are associated with the endoplasmic reticulum (Symens et al., 2012). Thus, the efficiency of foreign DNA delivery in dividing cells will depend on the amount of intact DNA present at the moment of cell division nearby the chromatin. Live imaging experiments carried out for lipoplexes (Kirchenbuechler et al., 2016) and polyplexes (Durymanov et al., 2015) has shown that $85-90 \%$ of transfected cells acquired the gene expression definitely after passing through mitosis. In light of the significant contribution of cell division to transfection, two strategies have been proposed to optimize DNA engulfment into daughter cell nuclei. The first approach proposed pre-condensation of DNA with a CdK1-responsive peptide before formation of lipoplexes. It was hypothesized that after the endosomal escape, these peptides stay in complex with DNA in cytosol and protect DNA from cytosolic nucleases, but dissociate during mitosis providing nuclear entrapment of the higher amount of nondamaged DNA. It turned out that DNA pre-condensation slightly increased transfection efficacy, but irrelevant to the nature of the peptide used for DNA pre-condensation (Remaut et al., 2014). The second strategy, proposed in the same study, aimed at specific anchoring of plasmid DNA to chromatin in newly formed nuclei due to pre-condensation of DNA with chromatin targeting peptides from the Kaposi's sarcoma-associated herpes virus. However, in spite of increased transfection, the nature

TABLE 2 | Main strategies to facilitate nuclear uptake of DNA delivered using non-viral vectors.

\begin{tabular}{ll}
\hline Strategy & Proposed mechanism \\
\hline Conjugation of NLS to DNA & $\begin{array}{l}\text { Importin-mediated transfer of DNA to the nucleus } \\
\text { via NPC }\end{array}$ \\
$\begin{array}{l}\text { Modification of nucleotide } \\
\text { sequence with transcription factor } \\
\text { binding sites }\end{array}$ & $\begin{array}{l}\text { Interaction of DNA with transcription factors in } \\
\text { cytosol followed by importin-mediated translocation } \\
\text { Pre-treatment with TCHD }\end{array}$ \\
$\begin{array}{l}\text { to the nucleus } \\
\text { Conjugation of nanocarrier with }\end{array}$ & $\begin{array}{l}\text { macromolecules } \\
\text { Interaction with retinoic acid receptor promotes }\end{array}$ \\
ATRA & NPC dilation and nuclear translocation of \\
ligand/receptor complex
\end{tabular}

Conjugation of nanocarrier with dexamethasone

Optimization of DNA uptake by daughter cell nuclei during mitosis
Interaction with glucocorticoid receptor promotes NPC dilation and nuclear translocation of ligand/receptor complex

- Pre-condensation of DNA with a CdK1-responsive peptide before lipoplex formation was thought to promote DNA protection in $\mathrm{G}_{0} / \mathrm{G}_{1}, \mathrm{~S}$, and $\mathrm{G}_{2}$, but dissociation and nuclear uptake during mitosis

- Pre-condensation of DNA with chromatin targeting peptides before lipoplex formation was thought to provide binding of DNA with chromosomes during mitosis and improved nuclear uptake

\section{Outcome}

Very contradictory results, the latest study indicated no transfection augmentation after NLS conjugation (van der Aa et al., 2005); no in vivo follow-up Improved transfection efficacy of cell culture (Dean et al., 1999; Mesika et al., 2001); no in vivo follow-up

- Enhanced lipoplex-mediated transfection (Vandenbroucke et al., 2007); no in vivo follow-up

Enhanced in vitro transfection mediated by ATRA-modified polyplexes (Park et al., 2009)

- No augmentation of transfection efficacy in A549 tumor nodules in lungs upon intravenous administration of ATRA-modified cationic liposomes (Charoensit et al., 2010) HA/PEI-dexamethasone/DNA ternary complexes demonstrated improved transfection of cancer cells and more efficiently inhibited HepG2 tumor growth (Fan et al., 2013)

Both approaches slightly increased transfection efficacy of HeLa and A549 cultured cells by lipoplexes with pre-condensed DNA, but irrelevant to the nature of the peptide used for DNA pre-condensation (Remaut et al., 2014); no in vivo follow-up 
of the peptide also did not seem to be the main reason for improvement (Remaut et al., 2014).

Mitosis-dependent transfection of cells may be significantly limited in cell lines with infrequent cell division. Remarkably, even without NLS and other nucleus-targeting sequences, lipoplex- or polyplex-formulated DNA can reach the nucleus in a mitosis-independent manner according to live-cell microscopy data (Durymanov et al., 2015; Kirchenbuechler et al., 2016). Some data supporting this finding were previously obtained by additional indirect methods including flow cytometry (Brunner et al., 2002; Grosse et al., 2006; Matz et al., 2013). The mechanisms underlying mitosis-independent non-viral gene delivery are still unknown. In the case of polyplexes, they are mostly attributed to the ability of polycations to permeabilize the nuclear envelope (Grandinetti and Reineke, 2012; Grandinetti et al., 2012), whereas mitosis-independent nuclear entry of lipoplexformulated DNA is thought to occur via direct fusion of lipoplexcontaining endosomes with the nuclear membrane (Elouahabi and Ruysschaert, 2005). However, direct experimental proofs of the mentioned mechanisms are still lacking.

\section{IMPACT OF INTRACELLULAR BARRIERS ON NON-VIRAL TRANSFECTION}

Intracellular penetration of nucleic acid nanoformulations seems to be a relatively effective process, although several studies state that cellular uptake efficacy has a direct impact on the transfection process (Sakaguchi et al., 2008; Trusov et al., 2011; Ulasov et al., 2011; Bishop et al., 2016). Hence, modulation of the cellular internalization process via variation of nanoparticle design and receptor targeting may accelerate uptake and increase internalized genetic material amount, resulting in higher transfection efficacy.

Endosomal escape, or the endosomal membrane, is a significant barrier which strongly affects the success of nucleic acid non-viral delivery. Time-lapse microscopy studies determined that there is from one to five release events per cell over several hours in the case of both lipoplexes (Wittrup et al., 2015) and polyplexes (ur Rehman et al., 2013). In the latter study the authors also estimated the frequency of release events by transfection of cells with nanoparticles carrying a mixture of two differently labeled short ( $\sim 20 \mathrm{bp})$ DNA fragments in a 1:1 ratio (red and green), or a mixture of two types of nanoparticles, each containing only single-labeled DNA (either red or green). In case of lipo- or polyplexes with double-labeled genetic payload all transfected cells contained both types of DNA fragments released from endosomes, whereas in the case of the mixture of nanoparticles with single-labeled DNA the values were different. For polyplexes, two types of DNA fragments were present in 23\% of transfected cells whereas the other $77 \%$ of transfected cells contained either green or red fragments. For lipoplexes, $80 \%$ of transfected cells contained two types of oligonucleotides and $20 \%$ were single-positive. These values enable us to calculate an average number of release events per cell for lipoplexes $\mathrm{N}_{l p}$ and polyplexes $\mathrm{N}_{\mathrm{pp}}$. The probabilities that transfected cells will get two types of DNA fragments in assumption of their release from different endosomal vesicles are $1-0.5^{\mathrm{Nlp}-1}=0.8$ for lipoplexes, and $1-0.5^{\mathrm{Npp}-1}=0.23$ for polyplexes (where $N_{\mathrm{lp}} \geq 1$ and $N_{\text {pp }} \geq 1$, because we consider only transfected cells). Resulting in values of $N_{\mathrm{pp}}=1.4$ and $N_{\mathrm{lp}}=3.3$, indicating almost twofold higher efficiency of endosomal escape in case of lipoplexes, although this conclusion only applies to certain carriers (22 $\mathrm{kDa}$ linear PEI for polyplexes and Lipofectamine 2000 for lipoplexes) used in this study. Actually, between one and five release events per cell over some hours have been observed for polyplexes (ur Rehman et al., 2013) and lipoplexes (Wittrup et al., 2015), indicating that only a very few number of nanoparticles overcome the endosomal barrier and contribute to transfection.

Regarding crossing the nuclear membrane barrier, numerous studies indicate a strong dependence of cell transfection on mitosis where the nuclear envelop is temporarily dismantled. Real-time microscopy of polyplex-mediated transfection has shown that cell division can result in only one post-mitotic transfected cell of the two; indicating non-uniform partitioning of plasmid DNA between the two daughter cells (Durymanov et al., 2015). Therefore transfection of the dividing cell is likely determined by only a few intact plasmids (probably originating from a single polyplex particle) in cytosol in close proximity to chromatin at the moment of mitosis. Most probably, the average number of intact DNA molecules released from Lipofectamine 2000-based lipoplexes is higher because singly transfected daughter cells were not detected during microscopy tracking of cells (Kirchenbuechler et al., 2016). It should be noted that transfection probability of actively dividing cells also depends on the cell cycle phase when DNA was released from endosome. For example, the highest transfection efficacy was observed for cells which entered mitosis 5-13 h after polyplex addition; approximately corresponding to early $\mathrm{S}$ phase (Durymanov et al., 2015). However, this time seems to be very variable for different cell lines and non-viral carriers. Interestingly, both lipo- and polyplexes can transfect non-dividing cells in culture. Because the vast majority of cancer cells in clinical tumors divide much slower than in the investigated cultured cell lines, the mechanism of mitosis-mediated DNA translocation might not be clinically relevant. In fact, transfection in non-dividing cells can occur, but efficacy of this process is too low and the mechanisms of nuclear DNA uptake are not determined. Elucidation of such mechanisms will likely provide effective tools for transfection of quiescent cells.

\section{OPTIMIZATION OF NUCLEIC ACID NANOFORMULATIONS FOR IN VIVO TRANSLATION}

Despite the importance of surmounting intracellular barriers by non-viral nanoparticles, the most significant fraction of effort to date is focused on safety/toxicity issues, improving biodistribution and tumor selectivity, and overcoming extracellular barriers, particularly, the tumor stromal barrier (Wang et al., 2015; Oliveira et al., 2016; Rezaee et al., 2016), because intratumoral extravasation and penetration of nucleic 
acid nanoformulations are very limited (Durymanov et al., 2013, 2016; Shen et al., 2014). These efforts are critical for the in vivo translation of the nucleic acid nanoformulations.

It should be noted that some aspects of nanoparticle tuning for in vivo translation are contradictory to the transfection efficacy on a cellular level. These discrepancies originate from the desired nature and properties of the nanocarrier. First, it must have a positive charge; either functional groups for electrostatic complexation or covalent attachment of nucleic acids. The positive charge of the nanocarrier protects genetic cargo form extracellular nucleases, facilitates interaction with the cell surface and uptake, and provides endosomal escape by interaction with anionic phospholipids in endosomal membrane. However, positive surface charge may also cause fast elimination of nucleic acid nanoformulations from circulation and off-target delivery of nucleic acids. The most common strategy to improve biodistribution in intravenously administered nanotherapeutics is shielding with neutral hydrophilic polymers like polyethylene glycol (PEG). PEGylation not only extends circulation time, but also improves diffusion-mediated permeation of tumor stroma due to minimization of electrostatic interactions with extracellular matrix (Nance et al., 2014). At the same time, functionalization with PEG impairs cellular uptake and may reduce endosomal escape efficacy. To solve this "PEG dilemma," different stimuli-responsive strategies can be exploited enabling, for example, a shedding PEG coat in the tumor environment or endosomes resulting in more efficient cellular uptake, endosomal release and gene silencing (Salzano et al., 2015). Another promising stimuli-responsive delivery system for nucleic acid delivery is lipid nanoparticles (LNP) based on lipids with protonable headgroups at endosomal $\mathrm{pH}$ (Del Pozo-Rodríguez et al., 2016). In extracellular space these carriers have neutral charge that provide long circulation times and higher tumor uptake, while in endosomes of cancer cells they acquire positive charge facilitating release of genetic cargo. Thus, the mentioned advantageous properties of LNPs resulted in their early clinical translation (Zatsepin et al., 2016), although the efficacy of endosomal escape for such LNPs (Gilleron et al., 2013), as well as cellular uptake (Sahay et al., 2013), are not very high and require additional optimization.

Another requirement of nanocarriers for delivery of nucleic acids is efficient internalization, which besides positive surface charge, can be modulated by functionalization with a ligand moiety. This modification for improvement of non-viral vectors on a cellular level has minimal conflict with in vivo application enhancing selectivity of tumor-targeted delivery, but potentially may impair nanoparticle penetration of tumor stroma due to "binding site barrier" effect detected for small targeted nanoparticles (Lee et al., 2010). For solving

\section{REFERENCES}

Becker, M. L., Fagan, J. A., Gallant, N. D., Bauer, B. J., Bajpai, V., Hobbie, E. K., et al. (2007). Length-dependent uptake of DNA-wrapped single-walled carbon nanotubes. Adv. Mater. 19, 939-945. doi: 10.1002/adma.200602667

Benjaminsen, R. V., Mattebjerg, M. A., Henriksen, J. R., Moghimi, S. M., and Andresen, T. L. (2013). The possible "Proton Sponge" effect of polyethylenimine this problem, modification of the nanocarrier with tumorpenetrating peptides can exploited. This technology enables tumor-specific extravasation and delivery of nucleic acid and other nanoformulations deep into the tumor parenchyma (Ren et al., 2012).

Finally, as opposed to in vitro use, very strict analysis of safety and biodegradability properties of nanocarriers should be carried out for clinical translation. Many types of cationic lipids or polycations commonly used for in vitro applications cannot be translated in vivo due to these issues. Additionally, modification of nanocarriers with virus- or bacteria-derived CPPs potentially holds immunogenicity limitations.

As a result, in spite of a diversity of nucleic acid delivery systems, only a limited number fulfills these in vivo requirements and maintains relatively high efficacy of overcoming intracellular barriers. We believe that ongoing (Yin et al., 2014; Zatsepin et al., 2016) and future clinical trials of these carriers including GalNAc conjugates, LNPs, and DPCs will provide an effective tool for anti-cancer gene-based therapy and clarify future prospects.

\section{CONCLUSION}

Despite progress in studying mechanisms of cell transfection by non-viral vectors and elucidation of the impact of intracellular barriers on transfection efficacy, some important information is still lacking. For instance, it is still unknown how endosomal phospholipids interact with nucleic acid nanoformulations. Based on knowledge about endosome maturation process, we hypothesized that negatively charged BMP/LBPA might be an important participant of this process. Additionally, clinically relevant mitosis-independent mechanisms of DNA translocation into the nuclei of cancer cells are unknown, ineffective, and not well-managed. Probably, their identification and exploitation will significantly improve transfection efficacy of quiescent tumor cells with DNA-containing non-viral nanoformulations.

Elucidation of transfection mechanisms is very important as it creates a strong basis for novel directions of nanocarrier improvement. We believe further analysis/understanding of endosomal escape and nuclear localization mechanisms will advance nucleic acid nanoformulations toward higher efficiency and enable clinical translation for numerous applications including cancer gene-based therapy.

\section{AUTHOR CONTRIBUTIONS}

Both authors listed have made a substantial, direct and intellectual contribution to the work, and approved it for publication.

(PEI) does not include change in lysosomal pH. Mol. Ther. 21, 149-157. doi: 10.1038/mt.2012.185

Bhattarai, S. R., Muthuswamy, E., Wani, A., Brichacek, M., Castañeda, A. L., Brock, S. L., et al. (2010). Enhanced gene and siRNA delivery by polycation-modified mesoporous silica nanoparticles loaded with chloroquine. Pharm. Res. 27, 2556-2568. doi: 10.1007/s11095-010-0 245-0 
Bishop, C. J., Majewski, R. L., Guiriba, T.-R. M., Wilson, D. R., Bhise, N. S., Quiñones-Hinojosa, A., et al. (2016). Quantification of cellular and nuclear uptake rates of polymeric gene delivery nanoparticles and DNA plasmids via flow cytometry. Acta Biomater. 37, 120-130. doi: 10.1016/j.actbio.2016.03.036

Bissig, C., and Gruenberg, J. (2014). ALIX and the multivesicular endosome: ALIX in Wonderland. Trends Cell Biol. 24, 19-25. doi: 10.1016/j.tcb.2013.10.009

Bohdanowicz, M., and Grinstein, S. (2013). Role of phospholipids in endocytosis, phagocytosis, and macropinocytosis. Physiol. Rev. 93, 69-106. doi: 10.1152/ physrev.00002.2012

Boussif, O., Lezoualc'h, F., Zanta, M. A., Mergny, M. D., Scherman, D., Demeneix, B., et al. (1995). A versatile vector for gene and oligonucleotide transfer into cells in culture and in vivo: polyethylenimine. Proc. Natl. Acad. Sci. U.S.A. 92, 7297-7301. doi: 10.1073/pnas.92.16.7297

Brunner, S., Fürtbauer, E., Sauer, T., Kursa, M., and Wagner, E. (2002). Overcoming the nuclear barrier: cell cycle independent nonviral gene transfer with linear polyethylenimine or electroporation. Mol. Ther. 5, 80-86. doi: 10.1006/mthe. 2001.0509

Cann, H. M., and Verhulst, H. L. (1961). Fatal acute chloroquine poisoning in children. Pediatrics 27, 95-102.

Caoduro, C., Hervouet, E., Girard-Thernier, C., Gharbi, T., Boulahdour, H., Delage-Mourroux, R., et al. (2017). Carbon nanotubes as gene carriers: focus on internalization pathways related to functionalization and properties. Acta Biomater. 49, 36-44. doi: 10.1016/j.actbio.2016.11.013

Carregal-Romero, S., Ochs, M., Rivera-Gil, P., Ganas, C., Pavlov, A. M., Sukhorukov, G. B., et al. (2012). NIR-light triggered delivery of macromolecules into the cytosol. J. Control. Release 159, 120-127. doi: 10.1016/j.jconrel.2011. 12.013

Charoensit, P., Kawakami, S., Higuchi, Y., Yamashita, F., and Hashida, M. (2010). Enhanced growth inhibition of metastatic lung tumors by intravenous injection of ATRA-cationic liposome/IL-12 pDNA complexes in mice. Cancer Gene Ther. 17, 512-522. doi: 10.1038/cgt.2010.12

Cheng, J., Zeidan, R., Mishra, S., Liu, A., Pun, S. H., Kulkarni, R. P., et al. (2006). Structure-function correlation of chloroquine and analogues as transgene expression enhancers in nonviral gene delivery. J. Med. Chem. 49, 6522-6531. doi: $10.1021 /$ jm060736s

Ciftci, K., and Levy, R. J. (2001). Enhanced plasmid DNA transfection with lysosomotropic agents in cultured fibroblasts. Int. J. Pharm. 218, 81-92. doi: 10.1016/S0378-5173(01)00623-8

Dean, D. A., Dean, B. S., Muller, S., and Smith, L. C. (1999). Sequence requirements for plasmid nuclear import. Exp. Cell Res. 253, 713-722. doi: 10.1006/excr.1999. 4716

Del Pozo-Rodríguez, A., Solinís, M. Á., and Rodríguez-Gascón, A. (2016). Applications of lipid nanoparticles in gene therapy. Eur. J. Pharm. Biopharm. 109, 184-193. doi: 10.1016/j.ejpb.2016.10.016

Durymanov, M. O., Beletkaia, E. A., Ulasov, A. V., Khramtsov, Y. V., Trusov, G. A., Rodichenko, N. S., et al. (2012). Subcellular trafficking and transfection efficacy of polyethylenimine-polyethylene glycol polyplex nanoparticles with a ligand to melanocortin receptor-1. J. Control. Release 163, 211-219. doi: 10.1016/j. jconrel.2012.08.027

Durymanov, M. O., Slastnikova, T. A., Kuzmich, A. I., Khramtsov, Y. V., Ulasov, A. V., Rosenkranz, A. A., et al. (2013). Microdistribution of MC1R-targeted polyplexes in murine melanoma tumor tissue. Biomaterials 34, 10209-10216. doi: 10.1016/j.biomaterials.2013.08.076

Durymanov, M. O., Yarutkin, A. V., Bagrov, D. V., Klinov, D. V., Kedrov, A. V., Chemeris, N. K., et al. (2016). Application of vasoactive and matrixmodifying drugs can improve polyplex delivery to tumors upon intravenous administration. J. Control. Release 232, 20-28. doi: 10.1016/j.jconrel.2016.04. 011

Durymanov, M. O., Yarutkin, A. V., Khramtsov, Y. V., Rosenkranz, A. A., and Sobolev, A. S. (2015). Live imaging of transgene expression in Cloudman S91 melanoma cells after polyplex-mediated gene delivery. J. Control. Release 215, 73-81. doi: 10.1016/j.jconrel.2015.07.028

Elouahabi, A., and Ruysschaert, J.-M. (2005). Formation and intracellular trafficking of lipoplexes and polyplexes. Mol. Ther. 11, 336-347. doi: 10.1016/ j.ymthe.2004.12.006

El-Sayed, A., and Harashima, H. (2013). Endocytosis of gene delivery vectors: from clathrin-dependent to lipid raft-mediated endocytosis. Mol. Ther. 21, 1118-1130. doi: $10.1038 / \mathrm{mt} .2013 .54$
Engel, S., Heger, T., Mancini, R., Herzog, F., Kartenbeck, J., Hayer, A., et al. (2011). Role of endosomes in simian virus 40 entry and infection. J. Virol. 85, 4198-4211. doi: 10.1128/JVI.02179-10

Falguières, T., Luyet, P.-P., and Gruenberg, J. (2009). Molecular assemblies and membrane domains in multivesicular endosome dynamics. Exp. Cell Res. 315, 1567-1573. doi: 10.1016/j.yexcr.2008.12.006

Fan, Y., Yao, J., Du, R., Hou, L., Zhou, J., Lu, Y., et al. (2013). Ternary complexes with core-shell bilayer for double level targeted gene delivery: in vitro and in vivo evaluation. Pharm. Res. 30, 1215-1227. doi: 10.1007/s11095-012-0960-9

Feldmann, D. P., Cheng, Y., Kandil, R., Xie, Y., Mohammadi, M., Harz, H., et al. (2018). In vitro and in vivo delivery of siRNA via VIPER polymer system to lung cells. J. Control. Release 276, 50-58. doi: 10.1016/j.jconrel.2018.02.017

Gamini, R., Han, W., Stone, J. E., and Schulten, K. (2014). Assembly of Nsp1 nucleoporins provides insight into nuclear pore complex gating. PLoS Comput. Biol. 10:e1003488. doi: 10.1371/journal.pcbi.1003488

Gilleron, J., Querbes, W., Zeigerer, A., Borodovsky, A., Marsico, G., Schubert, U., et al. (2013). Image-based analysis of lipid nanoparticle-mediated siRNA delivery, intracellular trafficking and endosomal escape. Nat. Biotechnol. 31, 638-646. doi: 10.1038/nbt.2612

Gonçalves, C., Mennesson, E., Fuchs, R., Gorvel, J.-P., Midoux, P., and Pichon, C. (2004). Macropinocytosis of polyplexes and recycling of plasmid via the clathrin-dependent pathway impair the transfection efficiency of human hepatocarcinoma cells. Mol. Ther. 10, 373-385. doi: 10.1016/j.ymthe.2004. 05.023

Graham, F. L., and van der Eb, A. J. (1973). A new technique for the assay of infectivity of human adenovirus 5 DNA. Virology 52, 456-467. doi: 10.1016/ 0042-6822(73)90341-3

Grandinetti, G., and Reineke, T. M. (2012). Exploring the mechanism of plasmid DNA nuclear internalization with polymer-based vehicles. Mol. Pharm. 9, 2256-2267. doi: 10.1021/mp300142d

Grandinetti, G., Smith, A. E., and Reineke, T. M. (2012). Membrane and nuclear permeabilization by polymeric pDNA vehicles: efficient method for gene delivery or mechanism of cytotoxicity? Mol. Pharm. 9, 523-538. doi: 10.1021/ mp200368p

Grosse, S., Thévenot, G., Monsigny, M., and Fajac, I. (2006). Which mechanism for nuclear import of plasmid DNA complexed with polyethylenimine derivatives? J. Gene Med. 8, 845-851. doi: 10.1002/jgm.915

Hafez, I. M., Maurer, N., and Cullis, P. R. (2001). On the mechanism whereby cationic lipids promote intracellular delivery of polynucleic acids. Gene Ther. 8, 1188-1196. doi: 10.1038/sj.gt.3301506

Harayama, T., and Riezman, H. (2018). Understanding the diversity of membrane lipid composition. Nat. Rev. Mol. Cell Biol. 19, 281-296. doi: 10.1038/nrm. 2017.138

Hill, A. B., Chen, M., Chen, C.-K., Pfeifer, B. A., and Jones, C. H. (2016). Overcoming gene-delivery hurdles: physiological considerations for nonviral vectors. Trends Biotechnol. 34, 91-105. doi: 10.1016/j.tibtech.2015.11.004

Hong, S., Leroueil, P. R., Janus, E. K., Peters, J. L., Kober, M.-M., Islam, M. T., et al. (2006). Interaction of polycationic polymers with supported lipid bilayers and cells: nanoscale hole formation and enhanced membrane permeability. Bioconjug. Chem. 17, 728-734. doi: 10.1021/bc060077y

Howe, S. J., Mansour, M. R., Schwarzwaelder, K., Bartholomae, C., Hubank, M., Kempski, H., et al. (2008). Insertional mutagenesis combined with acquired somatic mutations causes leukemogenesis following gene therapy of SCID-X1 patients. J. Clin. Invest. 118, 3143-3150. doi: 10.1172/JCI35798

Huschka, R., Barhoumi, A., Liu, Q., Roth, J. A., Ji, L., and Halas, N. J. (2012). Gene silencing by gold nanoshell-mediated delivery and laser-triggered release of antisense oligonucleotide and siRNA. ACS Nano 6, 7681-7691. doi: 10.1021/ nn301135w

Huschka, R., Zuloaga, J., Knight, M. W., Brown, L. V., Nordlander, P., and Halas, N. J. (2011). Light-induced release of DNA from gold nanoparticles: nanoshells and nanorods. J. Am. Chem. Soc. 133, 12247-12255. doi: 10.1021/ja204578e

Hutagalung, A. H., and Novick, P. J. (2011). Role of Rab GTPases in membrane traffic and cell physiology. Physiol. Rev. 91, 119-149. doi: 10.1152/physrev. 00059.2009

Jones, S. K., Lizzio, V., and Merkel, O. M. (2016). Folate receptor targeted delivery of siRNA and paclitaxel to ovarian cancer cells via folate conjugated triblock copolymer to overcome TLR4 driven chemotherapy resistance. Biomacromolecules 17, 76-87. doi: 10.1021/acs.biomac.5b01189 
Kam, N. W. S., Liu, Z., and Dai, H. (2006). Carbon nanotubes as intracellular transporters for proteins and DNA: an investigation of the uptake mechanism and pathway. Angew. Chem. 118, 591-595. doi: 10.1002/ange.200503389

Kichler, A., Leborgne, C., Coeytaux, E., and Danos, O. (2001). Polyethyleniminemediated gene delivery: a mechanistic study. J. Gene Med. 3, 135-144. doi: 10.1002/jgm.173

Kirchenbuechler, I., Kirchenbuechler, D., and Elbaum, M. (2016). Correlation between cationic lipid-based transfection and cell division. Exp. Cell Res. 345, 1-5. doi: 10.1016/j.yexcr.2014.11.019

Kleemann, E., Neu, M., Jekel, N., Fink, L., Schmehl, T., Gessler, T., et al. (2005). Nano-carriers for DNA delivery to the lung based upon a TAT-derived peptide covalently coupled to PEG-PEI. J. Control. Release 109, 299-316. doi: 10.1016/j. jconrel.2005.09.036

Kloeckner, J., Boeckle, S., Persson, D., Roedl, W., Ogris, M., Berg, K., et al. (2006). DNA polyplexes based on degradable oligoethylenimine-derivatives: combination with EGF receptor targeting and endosomal release functions. J. Control. Release 116, 115-122. doi: 10.1016/j.jconrel.2006.07.002

Kobayashi, T., Stang, E., Fang, K. S., de Moerloose, P., Parton, R. G., and Gruenberg, J. (1998). A lipid associated with the antiphospholipid syndrome regulates endosome structure and function. Nature 392, 193-197. doi: 10.1038/ 32440

Kobayashi, T., Startchev, K., Whitney, A. J., and Gruenber, J. (2001). Localization of lysobisphosphatidic acid-rich membrane domains in late endosomes. Biol. Chem. 382, 483-485. doi: 10.1515/BC.2001.059

Kopatz, I., Remy, J.-S., and Behr, J.-P. (2004). A model for non-viral gene delivery: through syndecan adhesion molecules and powered by actin. J. Gene Med. 6, 769-776. doi: 10.1002/jgm.558

Krpetic, Z., Nativo, P., Sée, V., Prior, I. A., Brust, M., and Volk, M. (2010). Inflicting controlled nonthermal damage to subcellular structures by laser-activated gold nanoparticles. Nano Lett. 10, 4549-4554. doi: 10.1021/nl103142t

Lai, W.-F., and Wong, W.-T. (2018). Design of polymeric gene carriers for effective intracellular delivery. Trends Biotechnol. 36, 713-728. doi: 10.1016/j.tibtech. 2018.02.006

Lee, H., Fonge, H., Hoang, B., Reilly, R. M., and Allen, C. (2010). The effects of particle size and molecular targeting on the intratumoral and subcellular distribution of polymeric nanoparticles. Mol. Pharm. 7, 1195-1208. doi: 10. $1021 / \mathrm{mp} 100038 \mathrm{~h}$

Legendre, J. Y., Trzeciak, A., Bohrmann, B., Deuschle, U., Kitas, E., and Supersaxo, A. (1997). Dioleoylmelittin as a novel serum-insensitive reagent for efficient transfection of mammalian cells. Bioconjug. Chem. 8, 57-63. doi: 10.1021/bc960076d

Li, J., Chen, Y.-C., Tseng, Y.-C., Mozumdar, S., and Huang, L. (2010). Biodegradable calcium phosphate nanoparticle with lipid coating for systemic siRNA delivery. J. Control. Release 142, 416-421. doi: 10.1016/j.jconrel.2009.11. 008

Li, L., Wen, Y., Xu, Q., Xu, L., Liu, D., Liu, G., et al. (2015). Application of carbon nanomaterials in gene delivery for endogenous RNA interference in vitro and in vivo. Curr. Pharm. Des. 21, 3191-3198. doi: 10.2174/ 1381612821666150531170219

Liu, L., Zheng, M., Renette, T., and Kissel, T. (2012). Modular synthesis of folate conjugated ternary copolymers: polyethylenimine-graft-polycaprolactoneblock-poly(ethylene glycol)-folate for targeted gene delivery. Bioconjug. Chem. 23, 1211-1220. doi: 10.1021/bc300025d

Lorenzi, G. L., and Lee, K.-D. (2005). Enhanced plasmid DNA delivery using anionic LPDII by listeriolysin O incorporation. J. Gene Med. 7, 1077-1085. doi: 10.1002/jgm.750

Ludtke, J. J., Zhang, G., Sebestyén, M. G., and Wolff, J. A. (1999). A nuclear localization signal can enhance both the nuclear transport and expression of 1 kb DNA. J. Cell Sci. 112(Pt 12), 2033-2041.

Luo, X., Peng, X., Hou, J., Wu, S., Shen, J., and Wang, L. (2017). Folic acidfunctionalized polyethylenimine superparamagnetic iron oxide nanoparticles as theranostic agents for magnetic resonance imaging and PD-L1 siRNA delivery for gastric cancer. Int. J. Nanomedicine 12, 5331-5343. doi: 10.2147/ IJN.S137245

Ma, D. (2014). Enhancing endosomal escape for nanoparticle mediated siRNA delivery. Nanoscale 6, 6415-6425. doi: 10.1039/c4nr00018h

Manno, C. S., Pierce, G. F., Arruda, V. R., Glader, B., Ragni, M., Rasko, J. J., et al. (2006). Successful transduction of liver in hemophilia by AAV-Factor IX and limitations imposed by the host immune response. Nat. Med. 12, 342-347. doi: $10.1038 / \mathrm{nm} 1358$

Matsuo, H., Chevallier, J., Mayran, N., Le Blanc, I., Ferguson, C., Fauré, J., et al. (2004). Role of LBPA and Alix in multivesicular liposome formation and endosome organization. Science 303, 531-534. doi: 10.1126/science.1092425

Matz, R. L., Erickson, B., Vaidyanathan, S., Kukowska-Latallo, J. F., Baker, J. R., Orr, B. G., et al. (2013). Polyplex exposure inhibits cell cycle, increases inflammatory response, and can cause protein expression without cell division. Mol. Pharm. 10, 1306-1317. doi: 10.1021/mp300470d

Mesika, A., Grigoreva, I., Zohar, M., and Reich, Z. (2001). A regulated, NFkappaBassisted import of plasmid DNA into mammalian cell nuclei. Mol. Ther. 3, 653-657. doi: 10.1006/mthe.2001.0312

Min, S.-H., Lee, D. C., Lim, M. J., Park, H. S., Kim, D. M., Cho, C. W., et al. (2006). A composite gene delivery system consisting of polyethylenimine and an amphipathic peptide KALA. J. Gene Med. 8, 1425-1434. doi: 10.1002/jgm. 973

Möbius, W., Donselaar, E. V., Ohno-Iwashita, Y., Shimada, Y., Heijnen, H. F. G., Slot, J. W., et al. (2003). Recycling compartments and the internal vesicles of multivesicular bodies harbor most of the cholesterol found in the endocytic pathway. Traffic 4, 222-231. doi: 10.1034/j.1600-0854.2003.00072.x

Mohammed-Saeid, W., Chitanda, J., Al-Dulaymi, M., Verrall, R., and Badea, I. (2017). Design and evaluation of RGD-modified gemini surfactant-based lipoplexes for targeted gene therapy in melanoma model. Pharm. Res. 34, 1886-1896. doi: 10.1007/s11095-017-2197-0

Nance, E., Zhang, C., Shih, T.-Y., Xu, Q., Schuster, B. S., and Hanes, J. (2014). Brainpenetrating nanoparticles improve paclitaxel efficacy in malignant glioma following local administration. ACS Nano 8, 10655-10664. doi: 10.1021/ nn504210g

Ng, Q. K. T., Sutton, M. K., Soonsawad, P., Xing, L., Cheng, H., and Segura, T. (2009). Engineering clustered ligand binding into nonviral vectors: alphavbeta3 targeting as an example. Mol. Ther. 17, 828-836. doi: 10.1038/mt.2009.11

Ngamcherdtrakul, W., Morry, J., Gu, S., Castro, D. J., Goodyear, S. M., Sangvanich, T., et al. (2015). Cationic polymer modified mesoporous silica nanoparticles for targeted siRNA delivery to HER2 ${ }^{+}$breast cancer. Adv. Funct. Mater. 25, 2646-2659. doi: 10.1002/adfm.201404629

Niut, Y., Popatt, A., Yu, M., Karmakar, S., Gu, W., and Yu, C. (2012). Recent advances in the rational design of silica-based nanoparticles for gene therapy. Ther. Deliv. 3, 1217-1237. doi: 10.4155/tde.12.98

Nomoto, T., Fukushima, S., Kumagai, M., Machitani, K., Arnida Matsumoto, Y., et al. (2014). Three-layered polyplex micelle as a multifunctional nanocarrier platform for light-induced systemic gene transfer. Nat. Commun. 5:3545. doi: 10.1038/ncomms4545

Oliveira, C., Ribeiro, A. J., Veiga, F., and Silveira, I. (2016). Recent advances in nucleic acid-based delivery: from bench to clinical trials in genetic diseases. J. Biomed. Nanotechnol. 12, 841-862. doi: 10.1166/jbn.2016.2245

Oliveira, S., Fretz, M. M., Høgset, A., Storm, G., and Schiffelers, R. M. (2007). Photochemical internalization enhances silencing of epidermal growth factor receptor through improved endosomal escape of siRNA. Biochim. Biophys. Acta 1768, 1211-1217. doi: 10.1016/j.bbamem.2007.01.013

Pantarotto, D., Singh, R., McCarthy, D., Erhardt, M., Briand, J.-P., Prato, M., et al. (2004). Functionalized carbon nanotubes for plasmid DNA gene delivery. Angew. Chem. Int. Ed. 43, 5242-5246. doi: 10.1002/anie.200460437

Park, K. M., Kang, H. C., Cho, J. K., Chung, I.-J., Cho, S.-H., Bae, Y. H., et al. (2009). All-trans-retinoic acid (ATRA)-grafted polymeric gene carriers for nuclear translocation and cell growth control. Biomaterials 30, 2642-2652. doi: 10.1016/ j.biomaterials.2009.01.025

Perez Ruiz de Garibay, A. (2016). Endocytosis in gene therapy with non-viral vectors. Wien. Med. Wochenschr. 1946, 227-235. doi: 10.1007/s10354-0160450-5

Pittella, F., Cabral, H., Maeda, Y., Mi, P., Watanabe, S., Takemoto, H., et al. (2014). Systemic siRNA delivery to a spontaneous pancreatic tumor model in transgenic mice by PEGylated calcium phosphate hybrid micelles. J. Control. Release 178, 18-24. doi: 10.1016/j.jconrel.2014.01.008

Ramamoorth, M., and Narvekar, A. (2015). Non viral vectors in gene therapy- an overview. J. Clin. Diagn. Res. 9, GE01-GE06. doi: 10.7860/JCDR/2015/10443. 5394

Raper, S. E., Chirmule, N., Lee, F. S., Wivel, N. A., Bagg, A., Gao, G., et al. (2003). Fatal systemic inflammatory response syndrome in a ornithine 
transcarbamylase deficient patient following adenoviral gene transfer. Mol. Genet. Metab. 80, 148-158. doi: 10.1016/j.ymgme.2003.08.016

Rejman, J., Bragonzi, A., and Conese, M. (2005). Role of clathrin- and caveolaemediated endocytosis in gene transfer mediated by lipo- and polyplexes. Mol. Ther. 12, 468-474. doi: 10.1016/j.ymthe.2005.03.038

Remaut, K., Symens, N., Lucas, B., Demeester, J., and De Smedt, S. C. (2014). Cell division responsive peptides for optimized plasmid DNA delivery: the mitotic window of opportunity? J. Control. Release 179, 1-9. doi: 10.1016/j.jconrel.2014. 01.013

Ren, Y., Cheung, H. W., Maltzhan, G., von Agrawal, A., Cowley, G. S., Weir, B. A., et al. (2012). Targeted tumor-penetrating siRNA nanocomplexes for credentialing the ovarian cancer oncogene ID4. Sci. Transl. Med. 4:147ra112. doi: $10.1126 /$ scitranslmed. 3003778

Rezaee, M., Oskuee, R. K., Nassirli, H., and Malaekeh-Nikouei, B. (2016). Progress in the development of lipopolyplexes as efficient non-viral gene delivery systems. J. Control. Release 236, 1-14. doi: 10.1016/j.jconrel.2016.06.023

Rozema, D. B., Lewis, D. L., Wakefield, D. H., Wong, S. C., Klein, J. J., Roesch, P. L., et al. (2007). Dynamic PolyConjugates for targeted in vivo delivery of siRNA to hepatocytes. Proc. Natl. Acad. Sci. U.S.A. 104, 12982-12987. doi: 10.1073/pnas.0703778104

Sahay, G., Alakhova, D. Y., and Kabanov, A. V. (2010). Endocytosis of nanomedicines. J. Control. Release 145, 182-195. doi: 10.1016/j.jconrel.2010.01. 036

Sahay, G., Querbes, W., Alabi, C., Eltoukhy, A., Sarkar, S., Zurenko, C., et al. (2013). Efficiency of siRNA delivery by lipid nanoparticles is limited by endocytic recycling. Nat. Biotechnol. 31, 653-658. doi: 10.1038/nbt.2614

Saito, G., Amidon, G. L., and Lee, K.-D. (2003). Enhanced cytosolic delivery of plasmid DNA by a sulfhydryl-activatable listeriolysin O/protamine conjugate utilizing cellular reducing potential. Gene Ther. 10, 72-83. doi: 10.1038/sj.gt. 3301859

Sakaguchi, N., Kojima, C., Harada, A., Koiwai, K., Emi, N., and Kono, K. (2008). Effect of transferrin as a ligand of ph-sensitive fusogenic liposome-lipoplex hybrid complexes. Bioconjug. Chem. 19, 1588-1595. doi: 10.1021/bc800126s

Salzano, G., Costa, D. F., and Torchilin, V. P. (2015). siRNA delivery by stimuli-sensitive nanocarriers. Curr. Pharm. Des. 21, 4566-4573. doi: 10.2174/ 138161282131151013190410

Sebestyén, M. G., Ludtke, J. J., Bassik, M. C., Zhang, G., Budker, V., Lukhtanov, E. A., et al. (1998). DNA vector chemistry: the covalent attachment of signal peptides to plasmid DNA. Nat. Biotechnol. 16, 80-85. doi: 10.1038/nbt0198-80

Selbo, P. K., Weyergang, A., Høgset, A., Norum, O.-J., Berstad, M. B., Vikdal, M., et al. (2010). Photochemical internalization provides time- and space-controlled endolysosomal escape of therapeutic molecules. J. Control. Release 148, 2-12. doi: 10.1016/j.jconrel.2010.06.008

Shen, J., Kim, H.-C., Su, H., Wang, F., Wolfram, J., Kirui, D., et al. (2014). Cyclodextrin and polyethylenimine functionalized mesoporous silica nanoparticles for delivery of siRNA cancer therapeutics. Theranostics 4, 487497. doi: $10.7150 /$ thno. 8263

Simões, S., Slepushkin, V., Pires, P., Gaspar, R., de Lima, M. P., and Düzgüneş, N. (1999). Mechanisms of gene transfer mediated by lipoplexes associated with targeting ligands or $\mathrm{pH}$-sensitive peptides. Gene Ther. 6, 1798-1807. doi: 10. 1038/sj.gt.3301015

Sonawane, N. D., Szoka, F. C., and Verkman, A. S. (2003). Chloride accumulation and swelling in endosomes enhances DNA transfer by polyamine-DNA polyplexes. J. Biol. Chem. 278, 44826-44831. doi: 10.1074/jbc.M308643200

Sprong, H., van der Sluijs, P., and van Meer, G. (2001). How proteins move lipids and lipids move proteins. Nat. Rev. Mol. Cell Biol. 2, 504-513. doi: 10.1038/ 35080071

Stewart, M. P., Lorenz, A., Dahlman, J., and Sahay, G. (2016a). Challenges in carrier-mediated intracellular delivery: moving beyond endosomal barriers. Wiley Interdiscip. Rev. Nanomed. Nanobiotechnol. 8, 465-478. doi: 10.1002/ wnan. 1377

Stewart, M. P., Sharei, A., Ding, X., Sahay, G., Langer, R., and Jensen, K. F. (2016b). In vitro and ex vivo strategies for intracellular delivery. Nature 538, 183-192. doi: 10.1038/nature19764

Symens, N., Soenen, S. J., Rejman, J., Braeckmans, K., De Smedt, S. C., and Remaut, K. (2012). Intracellular partitioning of cell organelles and extraneous nanoparticles during mitosis. Adv. Drug Deliv. Rev. 64, 78-94. doi: 10.1016/j. addr.2011.11.012
Talcott, B., and Moore, M. S. (1999). Getting across the nuclear pore complex. Trends Cell Biol. 9, 312-318. doi: 10.1016/S0962-8924(99)01608-6

Taratula, O., Garbuzenko, O., Savla, R., Andrew Wang, Y., He, H., and Minko, T. (2011). Multifunctional nanomedicine platform for cancer specific delivery of siRNA by superparamagnetic iron oxide nanoparticles-dendrimer complexes. Curr. Drug Deliv. 8, 59-69. doi: 10.2174/156720111793663642

Torchilin, V. P., Levchenko, T. S., Rammohan, R., Volodina, N., PapahadjopoulosSternberg, B., and D'Souza, G. G. M. (2003). Cell transfection in vitro and in vivo with nontoxic TAT peptide-liposome-DNA complexes. Proc. Natl. Acad. Sci. U.S.A. 100, 1972-1977. doi: 10.1073/pnas.0435906100

Trusov, G. A., Ulasov, A. V., Beletkaia, E. A., Khramtsov, Y. V., Durymanov, M. O., Rosenkranz, A. A., et al. (2011). Investigation of transport and unpacking mechanisms of polyplexes for transfection efficacy on different cell lines. Dokl. Biochem. Biophys. 437, 77-79. doi: 10.1134/S1607672911020062

Ulasov, A. V., Khramtsov, Y. V., Trusov, G. A., Rosenkranz, A. A., Sverdlov, E. D., and Sobolev, A. S. (2011). Properties of PEI-based polyplex nanoparticles that correlate with their transfection efficacy. Mol. Ther. 19, 103-112. doi: 10.1038/ $\mathrm{mt} .2010 .233$

ur Rehman, Z., Hoekstra, D., and Zuhorn, I. S. (2013). Mechanism of polyplex- and lipoplex-mediated delivery of nucleic acids: real-time visualization of transient membrane destabilization without endosomal lysis. ACS Nano 7, 3767-3777. doi: $10.1021 / \mathrm{nn} 3049494$

van der Aa, M. A., Koning, G. A., d'Oliveira, C., Oosting, R. S., Wilschut, K. J., Hennink, W. E., et al. (2005). An NLS peptide covalently linked to linear DNA does not enhance transfection efficiency of cationic polymer based gene delivery systems. J. Gene Med. 7, 208-217. doi: 10.1002/jgm.643

Vandenbroucke, R. E., Lucas, B., Demeester, J., De Smedt, S. C., and Sanders, N. N. (2007). Nuclear accumulation of plasmid DNA can be enhanced by nonselective gating of the nuclear pore. Nucleic Acids Res. 35:e86. doi: 10.1093/nar/ gkm440

Varkouhi, A. K., Scholte, M., Storm, G., and Haisma, H. J. (2011). Endosomal escape pathways for delivery of biologicals. J. Control. Release 151, 220-228. doi: 10.1016/j.jconrel.2010.11.004

Wagner, E., Plank, C., Zatloukal, K., Cotten, M., and Birnstiel, M. L. (1992). Influenza virus hemagglutinin HA-2 N-terminal fusogenic peptides augment gene transfer by transferrin-polylysine-DNA complexes: toward a synthetic virus-like gene-transfer vehicle. Proc. Natl. Acad. Sci. U.S.A. 89, 7934-7938. doi: 10.1073/pnas.89.17.7934

Wakefield, D. H., Klein, J. J., Wolff, J. A., and Rozema, D. B. (2005). Membrane activity and transfection ability of amphipathic polycations as a function of alkyl group size. Bioconjug. Chem. 16, 1204-1208. doi: 10.1021/bc050 $067 \mathrm{~h}$

Wang, H., Jiang, Y., Peng, H., Chen, Y., Zhu, P., and Huang, Y. (2015). Recent progress in microRNA delivery for cancer therapy by non-viral synthetic vectors. Adv. Drug Deliv. Rev. 81, 142-160. doi: 10.1016/j.addr.2014.10.031

Williams, R. L., and Urbé, S. (2007). The emerging shape of the ESCRT machinery. Nat. Rev. Mol. Cell Biol. 8, 355-368. doi: 10.1038/nrm2162

Wittrup, A., Ai, A., Liu, X., Hamar, P., Trifonova, R., Charisse, K., et al. (2015). Visualizing lipid-formulated siRNA release from endosomes and target gene knockdown. Nat. Biotechnol. 33, 870-876. doi: 10.1038/nbt.3298

Xiang, S., Tong, H., Shi, Q., Fernandes, J. C., Jin, T., Dai, K., et al. (2012). Uptake mechanisms of non-viral gene delivery. J. Control. Release 158, 371-378. doi: 10.1016/j.jconrel.2011.09.093

Xu, Y., and Szoka, F. C. (1996). Mechanism of DNA release from cationic liposome/DNA complexes used in cell transfection. Biochemistry 35, 56165623. doi: 10.1021/bi9602019

Yao, J., Fan, Y., Li, Y., and Huang, L. (2013). Strategies on the nuclear-targeted delivery of genes. J. Drug Target. 21, 926-939. doi: 10.3109/1061186X.2013. 830310

Yin, H., Kanasty, R. L., Eltoukhy, A. A., Vegas, A. J., Dorkin, J. R., and Anderson, D. G. (2014). Non-viral vectors for gene-based therapy. Nat. Rev. Genet. 15, 541-555. doi: 10.1038/nrg3763

Zamora, G. M., Wang, F., Sun, C.-H., Trinidad, A., Kwon, Y. J., Cho, S. K., et al. (2014). Photochemical internalization-mediated nonviral gene transfection: polyamine core-shell nanoparticles as gene carrier. J. Biomed. Opt. 19:105009. doi: 10.1117/1.JBO.19.10.105009

Zanta, M. A., Belguise-Valladier, P., and Behr, J.-P. (1999). Gene delivery: a single nuclear localization signal peptide is sufficient to carry DNA to the 
cell nucleus. Proc. Natl. Acad. Sci. U.S.A. 96, 91-96. doi: 10.1073/pnas.9 6.1 .91

Zatsepin, T. S., Kotelevtsev, Y. V., and Koteliansky, V. (2016). Lipid nanoparticles for targeted siRNA delivery - going from bench to bedside. Int. J. Nanomedicine 11, 3077-3086. doi: 10.2147/IJN.S106625

Zauner, W., Blaas, D., Kuechler, E., and Wagner, E. (1995). Rhinovirus-mediated endosomal release of transfection complexes. J. Virol. 69, 1085-1092.

Zhang, W., Rödl, W., He, D., Döblinger, M., Lächelt, U., and Wagner, E. (2015). Combination of sequence-defined oligoaminoamides with transferrinpolycation conjugates for receptor-targeted gene delivery. J. Gene Med. 17, 161-172. doi: 10.1002/jgm.2838

Zhang, X., Sawyer, G. J., Dong, X., Qiu, Y., Collins, L., and Fabre, J. W. (2003). The in vivo use of chloroquine to promote non-viral gene delivery to the liver via the portal vein and bile duct. J. Gene Med. 5, 209-218. doi: 10.1002/jg m. 340

Conflict of Interest Statement: The authors declare that the research was conducted in the absence of any commercial or financial relationships that could be construed as a potential conflict of interest.

Copyright $\odot 2018$ Durymanov and Reineke. This is an open-access article distributed under the terms of the Creative Commons Attribution License (CC BY). The use, distribution or reproduction in other forums is permitted, provided the original author(s) and the copyright owner(s) are credited and that the original publication in this journal is cited, in accordance with accepted academic practice. No use, distribution or reproduction is permitted which does not comply with these terms. 